\title{
Decisiones político-electorales de los ciudadanos en México
}

\author{
Angélica MENDIETA RAMíREZ \\ Benemérita Universidad Autónoma de Puebla (México) \\ angelicamendietaramirez@yahoo.com.mx
}

Recibido: $25 / 10 / 2012$

Aceptado: 23/01/2013

\begin{abstract}
Resumen
Conocer las motivaciones y mecanismos que conducen a las decisiones político-electorales de los ciudadanos, es una de las preocupaciones centrales de la comunicación política; de los actores políticos y de los partidos en contienda. En este trabajo, se pretende dilucidar algunos de los factores que se deben considerar a la hora de realizar un análisis de los procesos sociales, políticos y culturales que inciden en las orientaciones del voto de los ciudadanos mexicanos. Recientemente, el primero de julio del año en curso, México vivió un proceso electoral federal altamente competitivo y con niveles históricos de participación ciudadana que sirven de base para las reflexiones que a continuación se presentan.

Palabras clave: Decisiones políticas, sistema político mexicano, comunicación política, ciudadanía, legitimidad
\end{abstract}

\section{Electoral Political Decisions of the Mexican Citizens}

\begin{abstract}
Know the motivations and mechanisms that lead to the electoral decisions, is one OF the central concerns of political comunication; political actors and parties in conflict. This work aims to elucidate some of the factors that should be considered when performing an analysis of the social, political and cultural processes that affect Mexican citizens voting guidelines. Recently, the first of July of the current year, Mexico lived a federal electoral process highly competitive and with historic levels of citizen participation that serve as the basis for the thoughts that are presented below.

Keywords: Political Decisions, Mexican Politician System, Political Communication, Citizenship, Legitimacy.

\section{Referencia normalizada}

MENDIETA RAMÍREZ, Angélica (2013): "Decisiones político-electorales de los ciudadanos en México". Estudios sobre el mensaje periodístico. Vol. 19. Núm. especial abril, págs.: 873-878. Madrid, Servicio de Publicaciones de la Universidad Complutense.
\end{abstract}

Sumario: 1. Introducción. 2. Metodología. 3. Desarrollo. 4. Conclusiones. 5. Referencias bibliográficas.

\section{Introducción}

La adecuada comprensión de las decisiones que los ciudadanos toman para orientar su actuar en la arena pública; es parte de la calidad democrática de una nación. Cada vez resulta más relevante identificar los caminos de participación de la ciudadanía en la configuración de los procesos político-electorales, que el conocimiento exhaustivo de la técnica jurídica y los procedimientos normativos que conducen a una elección. Pareciera que la identificación de las variables con las que se articula una decisión ciudadana, requiere de instrumentos provenientes del estudio de la cultura política y de la complejidad que describen los procesos de comunicación política.

Al entramado institucional que otorga legalidad a la participación electoral, se suma el entramado menos visible de los valores culturales y las aspiraciones con que actúan los ciudadanos. México no es la excepción a esta condición de las democracias 
contemporáneas. La calidad de un régimen democrático se ancla en su potencial para generar mejores condiciones de acceso de la ciudadanía a la toma de decisiones que le afectan. El voto y su ejercicio, produce un efecto virtuoso sobre la totalidad del sistema y dinamiza las posibilidades de consolidación de la pluralidad e inclusión de los distintos sectores que integran el tejido social desde donde se articulan las acciones ciudadanas en una elección.

"El sentido del despertar que detona la comunicación política, es precisamente la posibilidad de abrir espacios para la expresión del ser como conciencia de estar en el mundo en una deriva constante de acciones que producen a la sociedad civil. Lo cívico sólo será posible en sociedad y se construye sociedad por medio de la comunicación, por el aprendizaje transformador de las acciones comunes, del lenguaje compartido, de la palabra rescatada y del silencio derrotado." (Mendieta, 2011: 45-47)

\section{Metodología}

La metodología de investigación es cualitativa y tiene dos enfoques: explicativo y correlacional con la finalidad de articular un modelo para la comprensión de los factores que inciden en la orientación del actuar ciudadano. A continuación se explican las dimensiones y actores que se muestran en el modelo diagramado.

Partiendo del sistema político y teniendo como encuadre de los movimientos multidimensionales del bucle, se encuentran por un lado, la exigencia de legalidad y la demanda ciudadana de legitimidad. La legalidad implica la formalización normativa con objetivos de control y la legitimidad representa el papel del consenso como catalizador de la confianza ciudadana en las instituciones y el reconocimiento de su gestión. De esta forma, el bucle de la comunicación política, establece la correlación y vigencia del contrato a través de la legalidad y la fuerza de la corresponsabilidad ciudadana con las acciones de las instituciones legitimadas.

\section{Desarrollo}

Por su parte, el sistema político ofrece el contexto en el que se sitúan las acciones de la totalidad del proceso evidenciado por el modelo del bucle. Sin la comprensión, la estabilidad y la existencia del sistema político en que se gestan las acciones comunicativas de la política, resultaría imposible comprender el sentido de los discursos generados desde los distintos niveles del entramado dinámico incorporados por el modelo. Es decir, todo proceso de comunicación política, así como su análisis y gestión, demanda el conocimiento del sistema político.

Las fuerzas que actúan en la totalidad del modelo son las nociones de aprender, transformar y disfrutar ${ }^{1}$. Cada una de ellas incide como energía que expresa el carácter y sentido de la acción comunicativa** subyacente al bucle de la comunicación política.

1 La descripción de estas tres nociones se inspira en la lectura de Juan Carlos Monedero que en su libro El gobierno de las palabras. Política para tiempos de confusión (2009) México: Fondo de Cultura Económica, propone estas tres nociones como parte de la indispensable reconstrucción del sentido de lo político y de la política como acción democratizadora del espacio público.

** En su Teoría de la acción comunicativa, Jürgen Habermas rescata el sentido social de la comunicación y su carácter activo mediante la elaboración dialógica de la verdad sin deslin- 
Se trata de aprender mediante la interacción dinámica y recursiva de los tejidos que integran el entramado del bucle; también se intenta transformar, gracias a la acción transformadora de la comunicación política, las condiciones en que se encuentran cada uno de los elementos sociales, culturales, políticos, ideológicos, comunicacionales y educativos que intervienen en la definición del fenómeno total sujeto de análisis mediante el instrumental conceptual y metodológico que aporta el bucle.

Por último, se busca disfrutar, como estrategia de solidaridad con el otro, con el que se encuentra a un lado. En el libre juego de los discursos que transitan del tejido social al cultural, del tejido político al ideológico, del tejido comunicacional al económico y las correspondencias multidireccionales entre todos ellos, construyen un todo comunicacional que aprende, transforma y disfruta en el proceso mismo de su construcción, deconstrucción y reconstrucción emergente desde todos los sitios como un rizoma que se escapa de la unicidad del discurso totalizador y estático del poder. El politólogo español Juan Carlos Monedero lo explica de la siguiente manera:

"Divertirse es una forma de solidaridad con el género humano. La risa contagia alegría. Porque ni la risa ni la diversión pueden ser constantemente un juego solitario. Disfrutar es hacer laico el gozo de vivir sin buhoneros de la trascendencia que quieren cobrar aquí la hipoteca del reposo eterno. Disfrutar sin que los frutos del disfrute roben la alegría a nadie, reír con y en los demás. Sentirse feliz con la felicidad ajena es la más alta señal de inteligencia humana." (2009: 58)

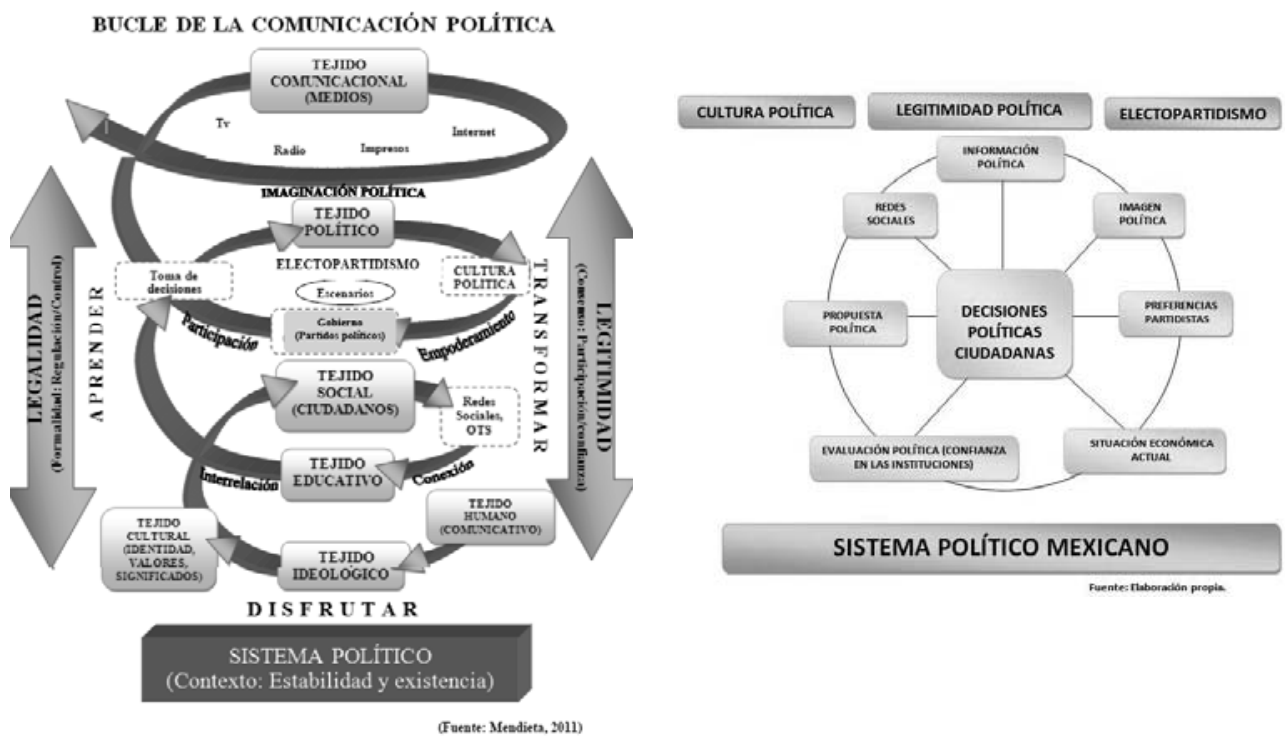

Como se puede observar, el modelo que ahora se presenta y que deriva del bucle de la comunicación política analizado en trabajos precedentes (Mendieta, 2011), hace posible identificar los elementos formales y los elementos informales que configuran

dar de ella la sustancia de la crítica post ilustrada de la razón, realizada en los desarrollos teóricos de la Escuela de Frankfurt. 
el campo de reflexión desde donde el ciudadano perfila su decisión política a favor de una u otra orientación partidista.

Por elementos formales de la decisión política ciudadana se entiende a todos aquellos que se encuentran institucionalizados por la norma jurídica y por los procedimientos derivados de ella. Asimismo, se hace referencia a fuerzas con un alto contenido de significación por el nivel de organización que presentan.

La siguiente dimensión, corresponde a lo que aquí se denomina elementos informales de la decisión política ciudadana, comprende factores y fuerzas que no se encuentran claramente regulados por la norma jurídica, pero que ejercen una influencia real en la definición de las orientaciones políticas de la ciudadanía. El nivel de organización de estos elementos informales no es muy alto, pero su capacidad de incidir, deriva de su potencial simbólico que produce un imaginario social capaz de volverse institución político-electoral.

En cada uno de los factores que muestra el modelo, se encuentran elementos formales e informales que inciden de forma directa o indirecta en los trazos de acción y decisión ciudadana. No se trata de un modelo que mantiene separados los factores, sino que evidencia su permanente imbricación para generar un entorno de significación que se expresa como modelo de comunicación política para la comprensión de los procesos de decisión ciudadana.

Claramente, esta propuesta forma parte de una investigación en curso, que busca establecer una propuesta metodológica para comprender la complejidad de un proceso cognitivo y metacognitivo tan complejo como lo es la decisión política de un ciudadano.

El sistema político mexicano, es un factor que otorga información a la totalidad de factores que articulan el modelo, es decir, del sistema político mexicano surgen los referentes a partir de los cuales se establecen las posiciones partidistas y en consecuencia, las opciones que se le presentan al ciudadano para ser capaz de elegir. En el sistema político mexicano existen elementos formales, tales como la Constitución Política de los Estados Unidos Mexicanos promulgada en 1917 y que continúa siendo la base jurídica para la dinámica política de México, pero también se presentan elementos informales como lo son los movimientos sociales que establecen puntos de agenda pública o el papel desempeñado por setenta años por el Partido Revolucionario Institucional como catalizador de fuerzas sociales y políticas.

Un ejemplo de cómo se manifiestan los elementos formales y los informales es el presidencialismo mexicano; la Constitución de 1917 establece el régimen presidencialista federal como la mejor forma de organizar a la República. A la luz de la Carta Magna, existen facultades presidenciales signadas por el constituyente, pero en la operación cotidiana del Poder Ejecutivo se presentan lo que en su momento Jorge Carpizo denominó facultades meta-constitucionales, con lo que intentaba mostrar el entramado no institucional que le otorgaba al Presidente de los Estados Unidos Mexicanos márgenes de acción que iban "más allá de la Constitución" sin violentar, paradójicamente, el sentido de la norma constitucional. (Carpizo, 1987)

La descripción del sistema político mexicano en este año 2012, implicaría una reflexión que escapa a los propósitos del presente trabajo; sin embargo se presentarán los trazos generales que lo caracterizan. 
Actualmente, el sistema político mexicano se caracteriza por un Presidente de la República limitado en sus posibilidades de acción política por la gran pluralidad de alternativas ideológicas expresadas en la Cámara de Diputados y en la de Senadores, así como el contrapeso que ejercen los gobernadores. Para comprender mejor esta condición, es necesario contrastar con la época en que el presidencialismo mexicano se caracterizaba por otorgar al titular del Poder Ejecutivo Federal, amplias facultades para articular sus decisiones, el control del Partido político más relevante y mayoritario en las dos Cámaras del Congreso de la Unión, así como el poder que ejercía sobre los Gobernadores que el mismo Presidente elegía para representar al partido Revolucionario Institucional en alguna entidad de la República.

Este escenario ha cambiado, desde finales de los años ochenta del siglo XX, México ha vivido un proceso de consolidación democrática que ha provocado mayores dificultades de acción al Presidente de la República. En su momento, cuando Vicente Fox llegó a la Presidencia de la República en el año 2000, en su discurso de toma de posesión enunció una frase que ha sido el destino del actual presidencialismo mexicano: "El Presidente propone y el Congreso dispone". La composición partidista en el Congreso obliga a negociaciones casi interminables entre el Poder Ejecutivo el Poder Legislativo; reformas importantes a la Constitución o iniciativas de ley que produzcan cambios estructurales en el país, exigen del Presidente de la República y de su Gabinete, el ejercicio de capacidades de negociación y una legitimidad social mayor.

Por otra parte, al perderse el control presidencial sobre los Gobernadores, se han producido opacidades y disfunciones sistémicas del sistema federalista mexicano, al punto que los gobernadores ejercen un poder casi total sobre sus estados sin necesidad de considerar la exigencia de acuerdos federales que faciliten la coordinación de acciones en beneficio de los ciudadanos y la transparencia en el manejo de los recursos. La soberanía formal que se reconoce a los Estados desde la propia Constitución Política, se transforma en una práctica de excepcionalismo a nivel regional o estatal.

Otro elemento no formal que ha ejercido cada vez mayor impacto en la evolución del sistema político mexicano, es el correspondiente a los medios masivos de comunicación y, en especial, la creciente influencia de las televisoras más grandes del país, TELEVISA y TV Azteca, en el establecimiento de condiciones apropiadas para la circulación de los discursos del Presidente de la República más allá de los tiempos oficiales asignados por la Dirección de Radio, Televisión y Cinematografía (RTC) dependiente de la Secretaría de Gobernación. En un entorno social y político, en el que la decisión de los ciudadanos tanto en las urnas, como fuera de ellas, adquiere mayor relevancia, la exposición de los políticos y del Presidente de la República en los medios de comunicación masiva, resulta indispensable para la consolidación de la legitimidad de dicho actor central de la política nacional.

Las redes sociales y el uso de Internet, ha adquirido mayor relevancia en los últimos seis años, conforme la cantidad de mexicanos en la red mundial de información ha crecido. Según datos de la Asociación Mexicana de Internet, en 2011 habíapoco más de 40 millones de mexicanos con acceso a Internet, mientras que en 2010 había 34.9 millones de internautas, esto implica un crecimiento entre el año 2010 y el 2011 del 14\% de usuarios. Según el mismo estudio, el tiempo de conexión de los mexica- 
nos en Internet es de 4.9 horas diarias y el 77\% de las actividades registradas por los usuarios se presentan en las redes sociales. (AMIPCI, 2012).

\section{Conclusiones}

Es evidente que el sistema político mexicano presenta cambios que obligan a un ejercicio político caracterizado por la disposición para negociar y establecer consensos legítimos entre los actores en conflicto.

Con esta nueva configuración del sistema político mexicano, de la cual sólo se explicaron algunos rasgos, es fácil deducir el entramado de conexiones de sentido que confluyen en la decisión política de un ciudadano. La democracia en México, ya no es la retórica de los poderosos sino que se convierte en una forma de vida altamente riesgosa pero, a la par, cargada de esperanzas. La calidad de la democracia en México, radica precisamente en la voluntad de los ciudadanos manifestada en las urnas. La apuesta es institucional, pero también es un reto para los políticos, porque deberán establecer criterios de diálogo democrático incluyente para dar cabida a la gran diversidad de demandas que se presentan a lo largo del territorio nacional.

El modelo que aquí se propone, servirá de base para indagar en qué condiciones se encuentra cada factor y su relación e incidencia para la definición de las decisiones político-electorales de los ciudadanos mexicanos. La multirreferencialidad y multidimensionalidad que presenta, contribuyen a una comprensión que atienda a la complejidad del proceso sujeto al análisis. Simplificar el proceso sólo acarreará confusiones en el estudio de las decisiones ciudadanas y en consecuencia cerrará el camino para la construcción de interpretaciones adecuadas de la comunicación política en México.

\section{Referencias bibliográficas}

ASOCIACIÓN MEXICANA DE INTERNET (2012): “Estudio de hábitos de los usuarios de Internet en México". www.amipci.org [Consultado: 8 de septiembre de 2012]

CARPIZO MCGREGOR, Jorge (1987): El presidencialismo mexicano. México, Siglo XXI Editores.

MENDIETA RAMÍREZ, Angélica y CASTILLO DURÁN, Jorge Luis (2011): “Confianza en las instituciones: un enfoque de la comunicación política”, en MENDIETA RAMÍREZ, Angélica y CASTILLO DURÁN, Jorge Luis (Coordinadores): Dimensiones de la comunicación política. México, Benemérita Universidad Autónoma de Puebla-LIMUSA.

\section{Dra. Angélica MENDIETA RAMÍREZ}

Benemérita Universidad Autónoma De Puebla (BUAP-México)

Facultad de Ciencias de la Comunicación

Profesora-Investigadora de Tiempo Completo

Miembro del Cuerpo Académico de "Comunicación Política"

angelicamendietaramirez@yahoo.com.mx 